\title{
A brief introductory guide to the ultrastructural analyses of plant tissues by using high-pressure freezing techniques
}

\author{
Ichirou Karahara $^{1}$, Yoshinobu Mineyuki ${ }^{2}$ \\ ${ }^{1}$ Department of Biology, Graduate School of Science and Engineering, University of Toyama, Toyama 930-8555, Japan \\ ${ }^{2}$ Department of Life Science, Graduate School of Life Science, University of Hyogo, 2167 Shosha, Himeji, Hyogo 671-2280, Japan \\ Author for correspondence: I. Karahara, karahara@sci.u-toyama.ac.jp
}

Summary: High-pressure freezing techniques have been developed in recent decades, and have proven to be immensely powerful for ultrastructural analyses of plant tissues. An increasing number of researchers and students of plant biology are interested in these techniques, and several different types of high-pressure freezing machine are available. The aim of this mini review is to provide the minimum basic knowledge for researchers who intend to freeze plant tissues by using high-pressure freezing techniques.

Key words: cryoprotectant, cytoskeleton, freeze substitution, high-pressure freezing, vitrification

\section{INTRODUCTION}

High-pressure freezing techniques have recently become well established. Detailed review articles outlining the theoretical aspects (Plattner and Bachmann 1982, Gilkey and Staehelin 1986, Dahl and Staehelin 1989, Studer et al. 1989) and practical issues (McDonald 2007, McDonald et al. 2007) are available. Although high-pressure freezing machines are expensive, several different types (for example, HPM100 and EM-PACT2; Leica Microsystems, Wetzlar, Germany) are commercially available, and are used by certain research facilities and universities. An increasing number of researchers and students in attendance at plant biology meetings and symposiums are interested in high-pressure freezing techniques. The aim of this mini review is to provide a brief introductory guide, and to outline the minimum basic knowledge required for researchers who intend to investigate plant structures by using highpressure freezing techniques. We will include the basic physics of ice-crystal formation (knowledge of which is required for cryofixation techniques) and provide tips for freezing plant tissues based on our experiences of handling onion epidermal tissues. In addition, we will introduce practical guides and publications regarding different plant materials.

Disadvantages of chemical fixation; requirement for highpressure freezing

Chemical fixatives are convenient to use on a daily basis. However, the molecules in tissues and cells can move before they are fixed, because chemical-penetration into cells is a simple diffusion process and it takes time for a fixative to reach the internal structures. In dividing Haemanthus cells, chromosomes move by as much as $0.5 \mu \mathrm{m}$ during chemical fixation, because it takes $10-30 \mathrm{sec}$ for a $3.1 \%$ glutaraldehyde solution to immobilize all of the cytoplasmic inclusions in the cells (Bajer and Molè-Bajer 1969, 1971). In Tradescantia stamen hair cells, immobilization of whole cell structures by $4 \%$ formaldehyde takes more than $10 \mathrm{~min}$ (Mineyuki and Gunning 1988; Figure 1). Other examples are summarized by Gilkey and Staehelin (1986). Consequently, chemical fixation can cause artifactual morphological changes, i.e., alteration of the original morphology, particularly at an ultrastructural level, in phenomena that occur within the time scale of the fixation process. Thus, analyses at high spatial resolution require rapid fixation and short acquisition times (Plattner and Bachmann 1982).

An alternative, more rapid method for the fixation of cellular components is ultrarapid freezing of specimens. This technique is termed cryofixation, or cryoimmobilization, and was developed to minimize the artifacts caused by conventional chemical fixation. Types of cryofixation include cold metal block freezing (Heuser et al. 1979), plunge freezing (Glick

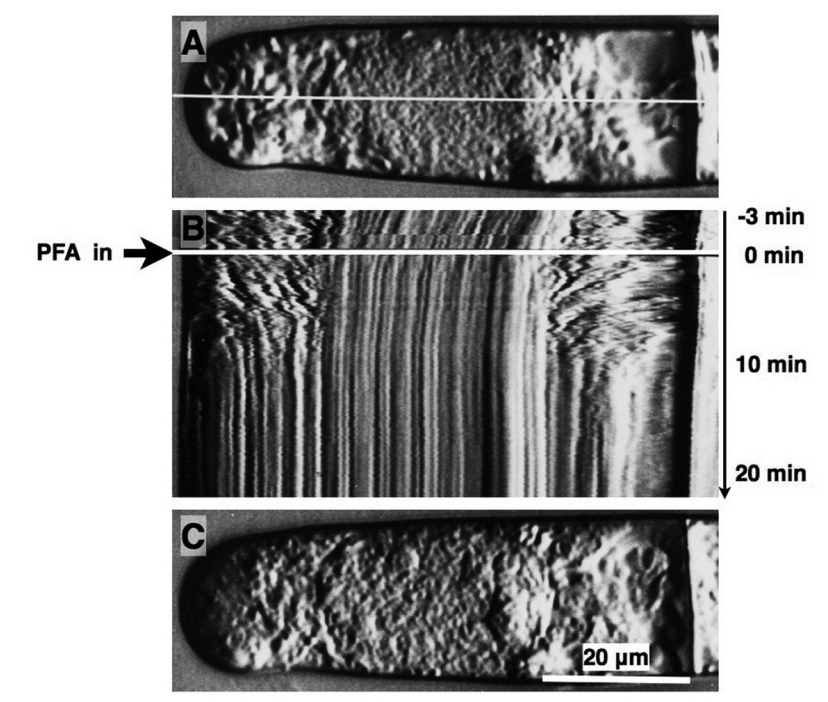

Figure 1 Kimographic analysis of changes in protoplasmic movement during the chemical fixation of a plant cell. (A) A living stamen hair cell of Tradescantia virgiana before $4 \%$ paraformaldehyde fixation. (B) Kimograms of the mid-longitudinal axis of the cell-white horizontal line drawn in (A) - before and after paraformaldehyde (PFA) fixation. The arrow on the right-hand side shows the time before or after the start of paraformaldehyde fixation (indicated by the short arrow on the lefthand side). From this, it can be seen that all of the protoplasm was fixed after $10 \mathrm{~min}$. (C) The same cell as in (A), but $50 \mathrm{~min}$ after the start of paraformaldehyde fixation. Modified from Figure 3 in Mineyuki and Gunning (1988). 
and Malmstrom 1952), spray freezing (Bachmann and Schmitt 1971), and propane jet freezing (Moor et al. 1976, Muller et al. 1980). The main problem occurring during the freezing of biological samples is damage caused by the growth of ice crystals (Bank and Mazur 1973; Figure 2C). Fibrillar material is typically observed in ultra-thin sections, because ice crystals push and exclude cytoplasmic constituents, and thereby cause the formation of fibrillar material around their periphery (Gilkey and Staehelin 1986). This symptom is relatively obvious in nuclei. The appearance of collapsed microtubules is also indicative of damage caused by ice crystals.

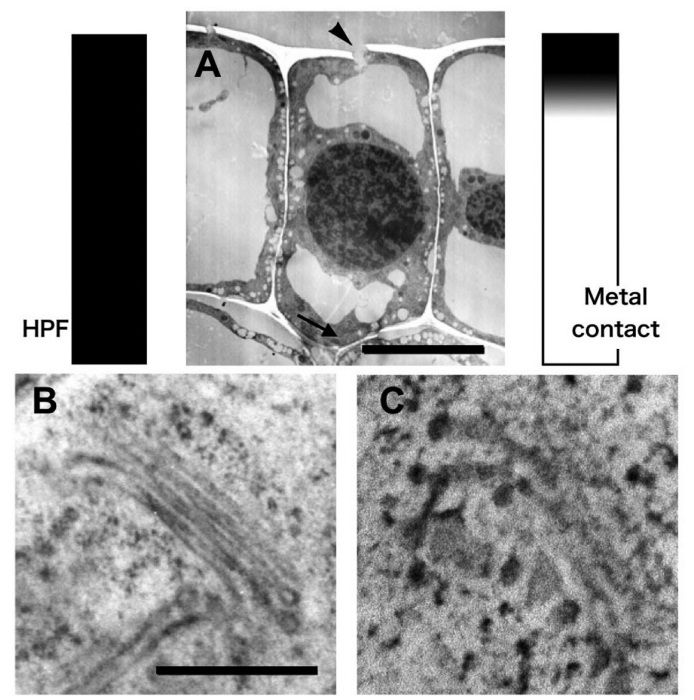

Figure 2 Electron micrographs of high-pressure frozen onion epidermal cells. (A) Transverse section of a prophase cell. The bars on each side of the micrograph show the difference in depth of a well-preserved area from the surface of a specimen frozen by using a high-pressure freezing (HPF) technique or the metal contact method. The filled area in each bar shows the well-preserved area. The arrowhead in the micrograph indicates the appearance of a crack during specimen preparation. Bar = $10 \mu \mathrm{m}$. (B) Magnified view of a Golgi apparatus (arrow in A), showing a well-preserved structure. Bar $=0.5 \mu \mathrm{m}$. (C) An example of a Golgi apparatus in which the structure is damaged by ice crystals. Modified from Figure 4 in Mineyuki et al. (2004).

\section{Cryofixation and ice-crystal formation}

We will now consider the process of freezing of water, i.e., solidification of water or ice-crystal formation. At atmospheric pressure, ice crystals, i.e., hexagonal ice, can form at $0^{\circ} \mathrm{C}$, i.e., the melting temperature of water $\left(T_{\mathrm{m}}\right)$. The normal fluid-tosolid phase transition of any liquid occurs through the processes of nucleation and growth (Franks 1982), which are described in previous reviews (Gilkey and Staehelin 1986, Wolfe and Bryant 1999). Briefly, when water starts to freeze, the water molecules form a small ice-like cluster, called the "nucleus". Nucleation can proceed via homogeneous or heterogeneous nucleation. In the former case, water molecules spontaneously form the "nuclei" (homogeneous "nuclei"). In the latter case, the "nuclei" are formed from a surface (such as the container wall) or from a large particle in the solution, which acts as a catalyst. However, the number of heterogeneous "nuclei" inside the cells is extremely low. If one of these "nuclei" reaches a critical radius, i.e., nucleation, then the ice will grow rapidly until total solidification occurs. If the water is cooled carefully, it can be maintained as a liquid, i.e., supercooled water (Mishima and Stanley 1998). For nucleation to occur, the area within this critical radius must be free of solutes (Wolfe and Bryant 1999). Consequently, the presence of solutes reduces the chance of nucleation occurring, or physically hinders nucleation, and for this reason, a cryoprotectant is used (see below). As the temperature of the water decreases, the critical radius of ice crystals decreases, and the average size of the "nucleus" of ice crystals increases. At approximately $-38^{\circ} \mathrm{C}$, the average size of the "nucleus" becomes equal to the critical radius, and therefore homogeneous, i.e., spontaneous, nucleation must occur. This temperature is called the temperature of homogeneous nucleation, $T_{\mathrm{h}}$ (Kanno et al. 1975). At or below $T_{\mathrm{h}}$, solidification of water will occur with minimal ice-crystal growth, because the water consists entirely of "nuclei" that exceed the critical size (Gilkey and Staehelin 1986).

The probability of nucleation is related to the sample volume, cooling rate, and viscosity of the liquid. As water is cooled, its viscosity increases. If water is cooled very fast, its viscosity becomes so high that rearrangements of the water molecules become very slow or stop (Wolfe and Bryant 1999). The presence of solutes increases the viscosity, and further slows this rearrangement. Consequently, nucleation and crystal growth are hindered, and water exists in a stable non-equilibrium phase, which is amorphous, but has mechanical properties similar to a solid, without significant ice-crystal growth. Such a phase is called a glass or vitrified solid (Wolfe and Bryant 1999), and the process is commonly referred to as specimen vitrification (Kopstad and Elgsaeter 1982).

At the ultrastructural analytical level, it is important to suppress the growth of ice crystals, such that they remain smaller than 10-15 nm (Dahl and Staehelin 1989). To fulfill this requirement, specimens must be cooled so rapidly that $T_{\mathrm{h}}$ is attained before nucleation occurs. Thereafter, the specimens must be maintained at or below $T_{\mathrm{h}}$ while solidification of water occurs (Gilkey and Staehelin 1986). This process requires cooling rates with temperature reductions in the order of magnitudes more than $10^{6}$ (Dahl and Staehelin 1989) or $10^{7} \mathrm{C} \mathrm{s}^{-1}$ (Wolfe and Bryant 1999) for pure water, and more than $10^{4} \mathrm{C} \mathrm{s}^{-1}$ for most biological specimens (Moor 1987). In practice, the removal of heat starts from the surface of specimens, and the low heat conductivity of water prevents such cooling rates from being achieved in the interior of specimens thicker than about $20 \mu \mathrm{m}$, even by using ultrarapid freezing techniques at atmospheric pressure (Dahl and Staehelin 1989).

\section{High-pressure freezing}

High-pressure freezing was developed to overcome the problems associated with conventional ultrarapid freezing techniques. High pressure inhibits an increase in the volume of water when it freezes, and thereby reduces the critical rate of freezing. This is required to ensure that ice crystals remain small, by changing the physical properties of water, i.e., 
lowering of $T_{\mathrm{m}}$, reduction in the rate of ice-crystal nucleation, and slowing of ice-crystal growth. In practice, $T_{\mathrm{m}}$ and $T_{\mathrm{h}}$ are reduced to a minimum of $-22^{\circ} \mathrm{C}$ and $-92^{\circ} \mathrm{C}$, respectively, at the most efficient pressure of approximately $200 \mathrm{MPa}$ (Kanno et al. 1975). Further, the ice crystals produced at this pressure are denser, and have lower nucleation and growth rates than hexagonal ice (Franks 1982).

High-pressure freezer models currently available at certain research facilities include the BAL-TEC HPM 010, Leica HPM100, and Leica EM-PACT (1 and 2). The detailed process of high-pressure freezing using the HPM 010 can be found in Dahl and Staehelin (Dahl and Staehelin 1989). Briefly, the pressure is maintained at $210 \mathrm{MPa}$ for $0.5 \mathrm{~s}$, and $100 \mathrm{~mL}$ of liquid nitrogen is insufflated onto the sample when the aperture size is $0.4 \mathrm{~mm}$. Alcohol is then insufflated for $15 \mathrm{msec}$, to avoid freezing of the sample before this high pressure is achieved. During this operation, the surface of the sample is cooled at a rate of $5 \times 10^{3 \circ} \mathrm{C} \mathrm{s}^{-1}$, meaning that the center $(600-\mu \mathrm{m}$ thickness $)$ is cooled at a rate of $5 \times 10^{2 \circ} \mathrm{C} \mathrm{s}^{-1}$ (Moor 1987). Based on this rate of cooling, the high pressure must be maintained for at least $0.3 \mathrm{~s}$ to cool a $0.6-\mathrm{mm}$ thick sample to $-150^{\circ} \mathrm{C}$; the HPM 010 fulfills this requirement. The detailed process of highpressure freezing using a Leica EM-PACT (1 and 2) is described elsewhere (Studer et al. 2001, McDonald et al. 2007). Figure 2A shows the difference in depth of a well-preserved area from the surface of a specimen frozen by using a high-pressure freezing technique or the metal contact method.

\section{Cryoprotection during high-pressure freezing}

The process of sample preparation by cutting plant tissues into pieces is carried out in a medium or buffer solution. The pieces of plant tissue are then placed in a carrier (Figure 3) containing the same solution, to prevent drying. However, when the cells are suspended in water or dilute buffer solution, freezing in the extracellular solution occurs before that inside individual cells. This is because the probability of nucleation of ice crystals is related to the sample volume, and the number of heterogeneous "nuclei" inside cells is extremely low (Wolfe and Bryant 1999). As mentioned above, nucleation and crystal growth are hindered by the presence of solutes and by increasing viscosity. In addition, ice crystals formed outside the specimens act as heat insulators, thereby reducing heat transfer from the specimens (McDonald et al. 2007).

For the same reasons, the impregnation of specimens with an antifreeze agent, i.e., a cryoprotectant, considerably reduces the freezing rate (Moor and Riehle 1968). Chemical cryoprotectants slow the growth of ice crystals, primarily by increasing the viscosity of the medium (MacKenzie et al. 1977). In this way, cryoprotectants help to suppress the formation of extracellular ice crystals, and thereby preserve the quality of the specimen during ultrarapid freezing (Dahl and Staehelin 1989). Cryoprotectants or cryoprotection were originally used to enhance the survival of cells subjected to slow freezing and subsequent thawing. Thus, the cryoprotectants mentioned in this mini review do not necessarily fulfill their original purpose
(Gilkey and Staehelin 1986).

Generally, non-penetrating cryoprotectants are recommended because, in comparison with penetrating cryoprotectants, they disrupt the cell structure less (McDonald et al. 2007). Non-penetrating cryoprotectants, such as sucrose and dextran, suppress the formation of extracellular ice crystals, which can induce the growth of intracellular ice crystals (Mazur 1970, Rasmussen et al. 1975, MacKenzie et al. 1977, Rasmussen 1982, Mazur 1984). The non-penetrating cryoprotectant, 1-hexadecene (Studer et al. 1989), can be used for plant tissues (Kaneko and Keegstra 1996), including onion cotyledons. Plant cells contain substances such as compatible solutes, to resist or adapt to osmotic stress; these substances are also considered to serve as cryoprotectants. In the case of onion root meristem cells, cryofixed seedlings grown in the presence of sucrose are better preserved than those grown in the absence of sucrose (Mineyuki et al. 2001). In our investigations, we germinate onion seeds by using an aqueous solution of $0.05 \mathrm{M}$ sucrose, and change the solution to $0.1 \mathrm{M}$ sucrose 1 day before freezing, because germination is affected by the presence of 0.1 $\mathrm{M}$ sucrose. In such a case, sucrose is considered to serve as a cryoprotectant by directly inhibiting the growth of extracellular ice crystals, as well as by enhancing the cellular cryoprotectant capability of plants.

Water evaporation from the cryoprotectant during preparation in a low-humidity environment may cause plasmolysis of cells. Thus, specimens must be prepared as rapidly as possible. Another frequently observed problem in specimens prepared by using high-pressure freezing is the artifactual crack fracture of a part of a cell (Figure 2A). This is caused by the presence of air bubbles outside the specimen,

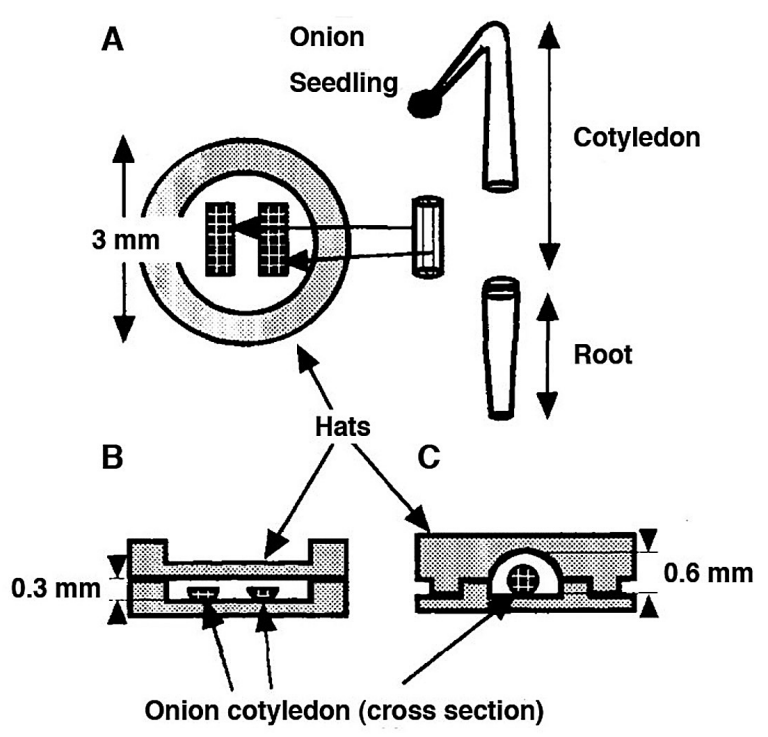

Figure 3 Schematic illustrations showing the method of specimen preparation for freezing. (A) A section is cut from the basal part of the onion cotyledon, split into 2 pieces, and placed inside a metal hat (a type of carrier used for the HPM 010) containing a cryoprotectant. (B) and (C) Longitudinal sectional views of the metal hats-used for embedding specimens in resin (B) or for freeze etching (C) - loaded with specimens. Adapted from Mineyuki et al. (2001). 
but inside the carrier. The collapse of air bubbles during pressurization can deform the specimen before freezing; the reexpansion of collapsed air bubbles during thawing can cause further deformation (Dahl and Staehelin 1989). Such air bubbles also act as heat insulators. Cracks appearing during highpressure freezing may additionally be caused by the retention of air bubbles within the apoplast of specimens (Dr. Pyoyun Park, Kobe University, personal communication).

\section{Freeze substitution}

Once specimens have been high-pressure frozen, they can be stored for a long time in liquid nitrogen (at a temperature of $-180^{\circ} \mathrm{C}$ ). However, care must be taken not to rewarm the specimens until the water is completely removed, particularly while undergoing transfer in liquid nitrogen or during the freezesubstitution process, because they are already under atmospheric pressure. Specimens must not be removed from the liquid nitrogen, and the forceps and other tools used during the freezesubstitution process must be precooled. Otherwise, amorphous ice starts to recrystallize and the ice crystal grows during rewarming. This process is called devitrification and starts at $-130^{\circ} \mathrm{C}$ in the case of pure water (Plattner and Bachmann 1982). The presence of solutes in the cytoplasm increases the devitrification temperature. Most biological materials display various recrystallization effects at temperatures ranging from $-80^{\circ} \mathrm{C}$ to $-50^{\circ} \mathrm{C}$ (Mazur 1961, Plattner and Bachmann 1982). Plattner and Bachmann (1982) recommended that all manipulations required subsequent to cryofixation should be performed at a temperature lower than $-80^{\circ} \mathrm{C}$. On the other hand, Gilkey and Staehelin (1986) found no evidence of recrystallization in a wide variety of samples freeze-substituted at temperatures between $-95^{\circ} \mathrm{C}$ and $-50^{\circ} \mathrm{C}$. McDonald et al. (2007) recommend that freeze substitution should be carried out at $-90^{\circ} \mathrm{C}$ by using a freeze-substitution device. In our investigations, we use dry ice $\left(-78.5^{\circ} \mathrm{C}\right)$ for convenience. The literatures relating to freeze substitution is documented by McDonald et al. (2007).

Freeze substitution involves the substitution of an organic solvent for frozen water, in specimens at low temperatures, typically ranging from $-80^{\circ} \mathrm{C}$ to $-90^{\circ} \mathrm{C}$. Acetone and osmium tetroxide $\left(\mathrm{OsO}_{4}\right)$ are commonly used as a solvent and a fixative, respectively. Acetone dissolves the frozen aqueous phase at $-90^{\circ} \mathrm{C}$, over a period of hours to days, whereas $\mathrm{OsO}_{4}$ is believed to be active at approximately $-30^{\circ} \mathrm{C}$ (Humbel and Müller 1986). As the temperature increases, fixatives react with cellular constituents. EM-grade acetone should be used without being dissolved in molecular sieves, because compounds in molecular sieves may react with $\mathrm{OsO}_{4}$ (Steinbrecht and Müller 1987). In our investigations, we treat onion specimens with $2 \%(\mathrm{w} /$ v) $\mathrm{OsO}_{4}$ at $40^{\circ} \mathrm{C}$, followed by $5 \%(\mathrm{w} / \mathrm{v})$ uranyl acetate, which are the optimal conditions for visualizing microfilaments, microtubules, and coated pits in the cytoplasm (Murata et al. 2002, Karahara and Kang 2013). Detailed descriptions of highpressure freezing and freeze-substitution processing of onion and Arabidopsis specimens are described by (Mineyuki et al.
2001, Karahara and Kang 2013), and Kang (2010), respectively. The techniques have also been applied to tobacco BY-2 suspension cells (Samuels et al. 1995), yeast (Giddings 2003, Osumi et al. 2006), and algae (Giddings 2003, Donohoe et al. 2006, Donohoe et al. 2007).

\section{Combination with other techniques}

Transient membrane systems in high-pressure-frozen, freezesubstituted specimens are exceptionally well preserved. Therefore, these specimens are extremely valuable for visualizing and quantitatively analyzing the ultrastructural features of 3-dimensional membrane transport by using electron tomography (Otegui et al. 2006, Kang and Staehelin 2008). We are currently using onion cotyledon epidermal cells to analyze the 3-dimensional distribution of transport vesicles at the preprophase band (Karahara et al. 2009, Karahara et al. 2010, Karahara et al. 2012). Electron tomographic analyses of highpressure-frozen, freeze-substituted specimens have been used to study cell plate formation, including phragmoplast organization (Otegui et al. 2001, Seguí-Simarro et al. 2004, Austin II et al. 2005, Otegui and Austin 2007). In our current investigations, we are using electron tomography to analyze microtubule dynamics at the preprophase band of onion epidermal cells (Figure 4). Practical guides for the immunolabeling of post-embedded specimens are also available (Kang 2010, Takeuchi et al. 2010).
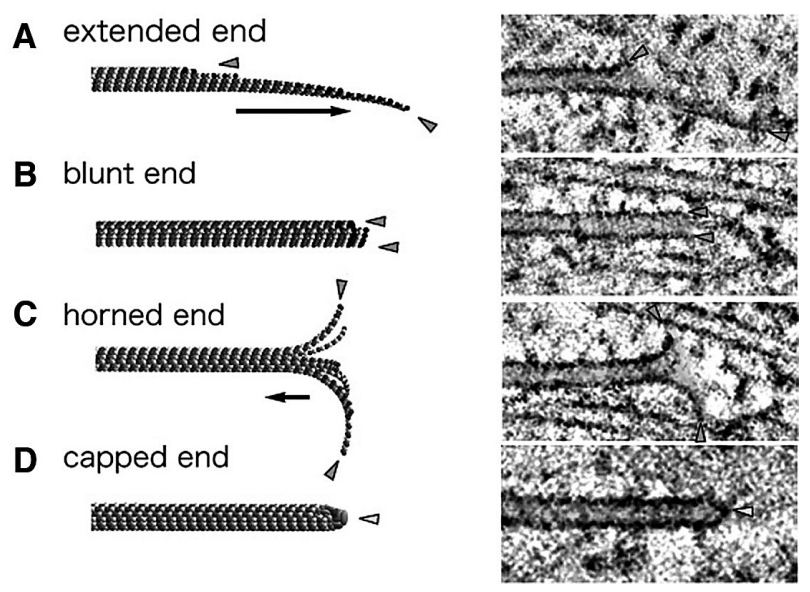

Figure 4 Tomographic images showing 4 typical types of microtubule end structure (right-hand panels) observed in onion epidermal cells, together with their corresponding models (left-hand panels). (A) Extended-end type. (B) Blunt-end type. (C) Horned-end type, considered to be formed when a microtubule is depolymerized. (D) Capped-end type, which is possibly a minus end capped by a $\gamma$-tubulin-ring complex. Modified from Figure 7 in Mineyuki et al. (2004).

\section{ACKNOWLEDGEMENT}

This work was supported by JSPS KAKENHI Grant No. 24620003 to I. K. and JSPS KAKENHI Grant No. 17207006 to Y. M.

\section{REFERENCES}

Austin II, J. R., Seguí-Simarro, J. M., and Staehelin, L. A. (2005) Quantitative analysis of changes in spatial distribution and plus-end 
geometry of microtubules involved in plant-cell cytokinesis. J Cell Sci 118: 3895-3903.

Bachmann, L., and Schmitt, W. W. (1971) Improved cryofixation applicable to freeze etching. Proc Natl Acad Sci USA 68: 2149.

Bajer, A., and Molè-Bajer, J. (1969) Formation of spindle fibers, kinetochore orientation, and behavior of the nuclear envelope during mitosis in endosperm. Chromosoma 27: 448-484.

Bajer, A., and Molè-Bajer, J. (1971) Architecture and function of the mitotic spindle. Adv Cell Mol Biol 1: 213-266.

Bank, H., and Mazur, P. (1973) Visualization of freezing damage. J Cell Biol 57: 729-742.

Dahl, R., and Staehelin, L. A. (1989) High-pressure freezing for the preservation of biological structure: Theory and practice. $J$ Electron Microsc Tech 13: 165-174.

Donohoe, B. S., Kang, B. H., and Staehelin, L. A. (2007) Identification and characterization of COPIa-and COPIb-type vesicle classes associated with plant and algal Golgi. Proc Natl Acad Sci USA 104: 163-168.

Donohoe, B. S., Mogelsvang, S., and Staehelin, L. A. (2006) Electron tomography of ER, Golgi and related membrane systems. Methods 39: $154-162$.

Franks, F. (1982) The properties of aqueous solutions at subzero temperatures. In: Water: A Comprehensive Treatise, Vol. 7, Franks, F. (ed), Plenum, New York, pp 215-338.

Giddings, T. H. (2003) Freeze-substitution protocols for improved visualization of membranes in high-pressure frozen samples. $J$ Microsc 212: 53-61.

Gilkey, J. C., and Staehelin, L. A. (1986) Advances in ultrarapid freezing for the preservation of cellular ultrastructure. $J$ Electron Microsc Tech 3: 177-210.

Glick, D., and Malmstrom, B. G. (1952) Studies in histochemistry XXIII. Simple and efficient freezing-drying apparatus for the preparation of embedded tissue. Exp Cell Res 3: 125-135.

Heuser, J. E., Reese, T. S., Dennis, M. J., Jan, Y., Jan, L., and Evans, L. (1979) Synaptic vesicle exocytosis captured by quick freezing and correlated with quantal transmitter release. J Cell Biol 81: 275-300.

Humbel, B., and Müller, M. (1986) Freeze substitution and low temperature embedding. In: The science of biological specimen preparation 1985, Scanning Electron Microscopy Inc, AMF O'Hare, Chicago, pp 175-183.

Kaneko, Y., and Keegstra, K. (1996) Plastid biogenesis in embryonic pea leaf cells during early germination. Protoplasma 195: 59-67.

Kang, B. H. (2010) Electron microscopy and high-pressure freezing of Arabidopsis. Methods Cell Biol 96: 259-283.

Kang, B. H., and Staehelin, L. A. (2008) ER-to-Golgi transport by COPII vesicles in Arabidopsis involves a ribosome-excluding scaffold that is transferred with the vesicles to the Golgi matrix. Protoplasma 234: 51-64.

Kanno, H., Speedy, R. J., and Angell, C. A. (1975) Supercooling of water to $-92^{\circ} \mathrm{C}$ under pressure. Science $189: 880-881$.

Karahara, I., and Kang, B. H. (2013) High-pressure freezing and low-temperature processing of plant tissue samples for electron microscopy. In: Plant Cell Morphogenesis: Methods and Protocols, Žárský, V., Cvrčková, F. (eds), The Humana Press Inc., Totoa, NJ (in press)

Karahara, I., Staehelin, L. A., and Mineyuki, Y. (2010) A role of endocytosis in plant cytokinesis. Commun Integr Biol 3: 1-3.

Karahara, I., Staehelin, L. A., and Mineyuki, Y. (2012) The role of endocytosis in the creation of the cortical division zone in plants. In: Molecular Regulation of Endocytosis, Ceresa, B. (ed), InTech, Rijeka, pp 41-60.

Karahara, I., Suda, J., Tahara, H., Yokota, E., Shimmen, T., Misaki, K., Yonemura, S., Staehelin, L. A., and Mineyuki, Y. (2009) The preprophase band is a localized center of clathrin-mediated endocytosis in late prophase cells of the onion cotyledon epidermis. Plant J 57: 819-831.

Kopstad, G., and Elgsaeter, A. (1982) Theoretical analysis of the ice crystal size distribution in frozen aqueous specimens. Biophys $J$ 40:
$155-161$.

MacKenzie, A. P., Derbyshire, W., and Reid, D. S. (1977) NonEquilibrium Freezing Behaviour of Aqueous Systems [and Discussion]. Philos Trans R Soc London B 278: 167-189.

Mazur, P. (1961) Physical and temporal factors involved in the death of yeast at subzero temperatures. Biophys $J$ 1: 247-264.

Mazur, P. (1970) Cryobiology: the freezing of biological systems. Science 168: 939-949.

Mazur, P. (1984) Freezing of living cells: mechanisms and implications. Am J Physiol-Cell Ph 247: C125-C142.

McDonald, K. (2007) Cryopreparation methods for electron microscopy of selected model systems. In: Cellular Electron Microscopy, McIntosh, J.R. (ed), Vol 79, Elsevier, Amsterdam, pp 23-56.

McDonald, K. L., Morphew, M., Verkade, P., and Muller-Reichert, T. (2007) Recent advances in high-pressure freezing. Methods Mol Biol 369: 143-173.

Mineyuki, Y., and Gunning, B. E. S. (1988) Streak time-lapse video microscopy: analysis of protoplasmic motility and cell division in Tradescantia stamen hair cells. J Microsc 150: 41-55

Mineyuki, Y., Karahara, I., Murata, T., Otegui, M., and Giddings, T. H. (2001) High pressure freezing in plant tissues. Denshi Kenbikyo 36: 105-107 (in Japanese).

Mineyuki, Y., Suda, J., and Karahara, I. (2004) Electron tomography. Plant Morphol 16: 21-30 (in Japanese)

Mishima, O., and Stanley, H. E. (1998) The relationship between liquid, supercooled and glassy water. Nature 396: 329-335.

Moor, H. (1987) Theory and practice of high pressure freezing. In: Cryotechniques in Biological Electron microscopy, Steinbrecht, R.A., Zierold, K. (eds), Springer-Verlag, Berlin pp 175-191.

Moor, H., Kistler, J., and Muller, M. (1976) Freezing in a propane jet. Experientia 32: 805-815.

Moor, H., and Riehle, U. (1968) Snap-freezing under high pressure: a new fixation technique for freeze-etching. Proc 4th Eur Reg Conf Electron Microsc 2: 33-34.

Muller, M., Meister, N., and Moor, H. (1980) Freezing in a propane jet and its application in freeze-fracturing. Mikroskopie 36: 129-140.

Murata, T., Karahara, I., Kozuka, T., Giddings Jr, T. H., Staehelin, L. A., and Mineyuki, Y. (2002) Improved method for visualizing coated pits, microfilaments, and microtubules in cryofixed and freezesubstituted plant cells. J Electron Microsc (Tokyo) 51: 133-136.

Osumi, M., Konomi, M., Sugawara, T., Takagi, T., and Baba, M. (2006) High-pressure freezing is a powerful tool for visualization of Schizosaccharomyces pombe cells: ultra-low temperature and low-voltage scanning electron microscopy and immunoelectron microscopy. J Electron Microsc (Tokyo) 55: 75-88.

Otegui, M. S., and Austin, J. R. (2007) Visualization of membranecytoskeletal interactions during plant cytokinesis. Methods Cell Biol 79: 221-240.

Otegui, M. S., Herder, R., Schulze, J., Jung, R., and Staehelin, L. A. (2006) The proteolytic processing of seed storage proteins in Arabidopsis embryo cells starts in the multivesicular bodies. Plant Cell 18: 2567-2581.

Otegui, M. S., Mastronarde, D. N., Kang, B. H., Bednarek, S. Y., and Staehelin, L. A. (2001) Three-dimensional analysis of syncytialtype cell plates during endosperm cellularization visualized by high resolution electron tomography. Plant Cell 13: 2033-2051.

Plattner, H., and Bachmann, L. (1982) Cryofxation: A tool in biological ultrastructural research. Int Rev Cytol 79: 237-304.

Rasmussen, D. H. (1982) Ice formation in aqueous systems. J Microsc 128: $167-174$.

Rasmussen, D. H., Macaulay, M. N., and MacKenzie, A. P. (1975) Supercooling and nucleation of ice in single cells. Cryobiology 12: 328-339.

Samuels, A. L., Giddings Jr, T. H., and Staehelin, L. A. (1995) Cytokinesis in tobacco BY-2 and root tip cells: a new model of cell plate formation in higher plants. J Cell Biol 130: 1345-1357.

Seguí-Simarro, J. M., Austin Ii, J. R., White, E. A., and Staehelin, L. A. (2004) Electron tomographic analysis of somatic cell plate formation 
in meristematic cells of Arabidopsis preserved by high-pressure freezing. Plant Cell 16: 836-856.

Steinbrecht, R. A., and Müller, M. (1987) Freeze-substitution and freezedrying. In: CryoTechniques in Biological Electron Microscopy, Steinbrecht, R.A., Zierold, K. (eds), Springer-Verlag, Berlin, pp 149172.

Studer, D., Graber, W., Al-Amoudi, A., and Eggli, P. (2001) A new approach for cryofixation by high-pressure freezing. $J$ Microsc 203: 285-294.

Studer, D., Michel, M., and Müller, M. (1989) High pressure freezing comes of age. Scanning Microsc Suppl 3: 253-268.

Takeuchi, M., Takabe, K., and Mineyuki, Y. (2010) Immunoelectron microscopy of cryofixed and freeze- substituted plant tissues. In: Immuno-electron Microscopy: Methods and Protocols, Schwartzbach, S., Osafune, T. (eds), The Humana Press Inc., Totoa, NJ, pp 155-164.

Wolfe, J., and Bryant, G. (1999) Freezing, drying, and/or vitrification of membrane-solute-water systems. Cryobiology 39: 103-129.

Received: 14 February 2013 